\title{
The analysis of percutaneous pedicle screw technique with guide wire-less in lateral decubitus position following extreme lateral interbody fusion
}

\author{
Akihiko Hiyama*, Daisuke Sakai, Masato Sato and Masahiko Watanabe
}

\begin{abstract}
Background: Lateral lumbar interbody fusion (LLIF) and bilateral percutaneous pedicle fixation are valuable, minimally invasive lateral approaches used to treat symptomatic degenerative disc disease. In the current procedure, the patient's position on the operating table is changed after LLIF surgery from the lateral decubitus to the prone position. The ability to perform both approaches with the patient in the same position should reduce operation time. Use of a guide wire is problematic during percutaneous pedicle screw (PPS) insertion using fluoroscopy with the patient in the lateral decubitus position. A new guide wire-less PPS system may solve this problem and reduce operation time. Here, we evaluated the operative data and efficacy for this technique.

Methods: This study included 30 patients (aged $70.8 \pm 8.5$ years; 17 men, 13 women) who underwent a combined operation (indirect decompression) using extreme lateral interbody fusion (XLIF) with only a single level for lumbar spinal canal stenosis and lumbar degenerative spondylolisthesis. Patient demographics and operative data were compared between two groups: patients who remained in the lateral decubitus position for pedicle screw fixation ( $L$ group) and those turned to the prone position (P group). Radiographic assessment was performed using pre- and postoperative anteroposterior and lateral lumbar films with measurement of lumbar lordosis, segmental lordosis, and segmental translation.

Results: We analyzed 18 patients in the P group and 12 in the L group. Age, sex, height, body weight, body mass index, estimated blood loss, and length of stay did not differ between groups. The operation time was 34 min shorter for the $L$ group (P group $111.9 \pm 25.0$ vs. $L$ group $77.5 \pm 22.2 \mathrm{~min}, p<0.01$ ). Pre- and postoperative lordosis, segmental lordosis, and segmental translation did not differ significantly between groups.

Conclusions: A single position after XLIF surgery is a feasible modification to the standard procedure when used with fluoroscopy and a guide wire-less PPS system. The time saved is the main advantage of inserting the PPS with the patient in the lateral decubitus position without repositioning. Use of the lateral PPS with a guide wire-less technique may help improve operative efficiency and reduce cost.
\end{abstract}

\section{Background}

Of the minimally invasive lateral lumbar interbody fusion (LLIF), extreme lateral interbody fusion (XLIF) and oblique lumbar interbody fusion (OLIF) are techniques used for indirect decompression of the neural structures through interbody distraction and fusion in the lumbar

* Correspondence: a.hiyama@tokai-u.jp

Department of Orthopaedic Surgery, Surgical Science, Tokai University

School of Medicine, 143 Shimokasuya, Isehara, Kanagawa 259-1193, Japan spine. Good results have been reported for these techniques [1-4].

Concomitant posterior fixation is often recommended because of the higher rates of nonunion after the LLIF procedure. In this case, the use of bilateral percutaneous pedicle screws (PPSs) is considered to be the gold standard [5]. In the current procedure, after the lateral access surgery, the patient is repositioned in the prone position for the pedicle screw fixation. This repositioning requires completing a second round of preparation, draping, and

(c) The Author(s). 2019 Open Access This article is distributed under the terms of the Creative Commons Attribution 4.0 International License (http://creativecommons.org/licenses/by/4.0/), which permits unrestricted use, distribution, and 
room positioning, which increases the operation time and cost because of the extra use of materials.

Some groups have described a technique in which the PPSs are placed while the patient remains in the lateral position following the LLIF. Ziino et al. reported that lateral PPS fixation following LLIF decreases the operating room time without compromising postoperative lordosis or the complication rate [6]. Lateral PPS surgery using three-dimensional (3D) neuronavigation, such as the O-arm system and navigation, has been reported [7]. However, few institutions have installed these instruments because of the cost.

The current procedure is to insert the PPS through the guide wire, and the setup is cumbersome in most cases. That is, it can be difficult to secure a working space between the patient and the fluoroscopy, and use of fluoroscopy during insertion of PPSs with the patient in the lateral decubitus position can be awkward for the surgeon (Fig. 1). With this as background, we thought that a lateral repositioning procedure (XLIF + lateral PPS) using a guide wire-less PPS system (Viper Prime ${ }^{\mathrm{TM}}$, DePuy Synthes Spine, Raynham, MA, USA) may be useful for solving these problems. In this study, we compared the operation time, amount of bleeding, and complications between patients who were in the prone position during PPS insertion (P group) with those who received PPS insertion after the conventional position change to the lateral decubitus position (L group). We also describe the lateral PPS procedure using guide wireless PPS.

\section{Materials and methods Included patients}

The inclusion criteria were patients aged $>18$ years who were undergoing a combined operation (indirect decompression) using XLIF with only single-level lumbar spinal canal stenosis (LCS) and lumbar degenerative spondylolisthesis (DS) at a single institute from January 2016 to June 2019. We conducted our retrospective review using a retrospective cohort. The exclusion criteria included patients who had undergone previous lumbar spinal surgery or those who were undergoing combined procedures including direct posterior decompression and posterior lumbar fusion.

In total, 30 patients (aged $70.8 \pm 8.5$ years; 17 men, 13 women) were included. The patient demographics (age, sex, height, body weight, and body mass index (BMI)) and operative data (blood loss, operation time, and change in hemoglobin $(\mathrm{Hb})$ level from before to the first day after surgery) were recorded. Radiographic assessment was performed using pre- and postoperative anteroposterior (AP) and lateral lumbar films; the lumbar lordosis, segmental lordosis, length of stay, and intraoperative complication rate were recorded.

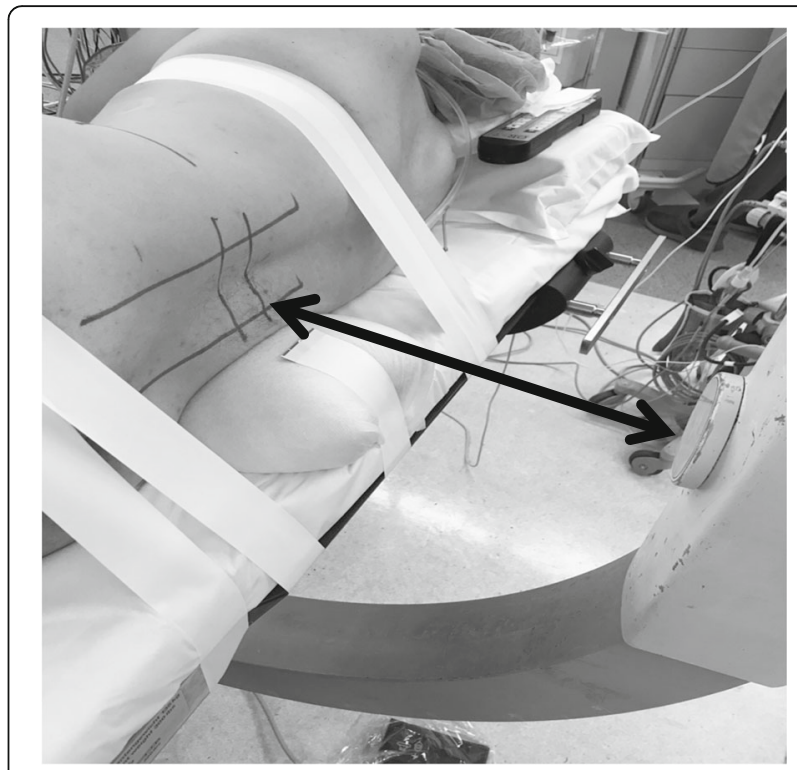

Fig. 1 Lateral decubitus position. During PPS insertion with a guide wire, it is difficult to secure a working space (arrow) between the patient and the fluoroscopy, and the use of fluoroscopy during insertion of PPS with the patient in the lateral decubitus position can be awkward for the surgeon

\section{Operative technique (XLIF and PPS fixation)}

Interbody fusion was completed using the XLIF technique as described by Ozgur et al. [3]. Briefly, the patient was placed in the lateral decubitus position with the hip at the level of the break in the operating table. The chest and hip areas were secured to the table with tape. A previous report has suggested that the patient's position is critical, and there was a slight learning curve for surgeons when performing the surgery involving insertion of the "downside" PPS with the patient in the lateral decubitus position [8]. For example, positioning the patient too far from the edge of the bed can limit the surgeon's ability to place the hand low enough to medialize the downside pedicle screws. However, this is less of a concern when performing a lateral PPS procedure using the Viper Prime ${ }^{\mathrm{TM}}$.

Once the position was decided, the XLIF was performed according to the previous method [3]. This facilitates access to the largest number of disc spaces with a relatively small incision. Blunt dissection was then used to access the disc spaces under fluoroscopic guidance. After removal of the disc material with a rongeur, a Cobb elevator was advanced gently under fluoroscopy guidance along the endplates to release the contralateral annulus. Cage size trials were followed by additional disc curettage and rasping of the endplates. All cages were inserted using two containment sliders to protect the endplates and to keep the graft material inside the cage. For all patients, the side-to-side cage size was decided 
according to the width of the endplates at that level based on intraoperative fluoroscopic guidance, and titanium cages with a standard $18 \mathrm{~mm}$ width were used. The maximum distraction achieved during discectomy using the trial inserts provided guidance as to the height of the cage. The choice of these XLIF cages (CoRoent XL; NuVasive Inc., San Diego, CA, USA) was decided by the surgeon. Cage lengths ranged from 45 to $55 \mathrm{~mm}$, and heights from 8 to $12 \mathrm{~mm}$.

The lateral PPS technique using the Viper Prime ${ }^{\mathrm{TM}}$ instrument is shown in Fig. 2. Following the XLIF, patients in the $\mathrm{P}$ group were turned to the prone position and then prepared again and draped. Bilateral PPS surgery was then performed with the patient in the prone position. Patients in the $\mathrm{L}$ group remained in the lateral decubitus position for PPS fixation. An image in the AP view was taken to mark the lateral radiographic borders of the pedicles for screw placement. Using a lateral view, the center of each pedicle was identified and marked. A small incision $2-3 \mathrm{~cm}$ lateral to the lateral radiographic borders of each pedicle was made for percutaneous exposure, and the stylets were then docked at the junction of the transverse process and the superior articular process. The stylets were then inserted with a hammer to hold the spot within the pedicles. After the stylets were inserted into the pedicle inner rim, an image in the AP view was taken to confirm in the lateral view that the posterior body wall had been reached. At that point, the $\mathrm{C}$-arm was then brought to a lateral position to maximize the working space for screw placement. After all screws had been inserted, a rod was passed percutaneously and secured to the screw heads using setscrews.

\section{Statistical analysis}

Statistical analyses were performed using IBM SPSS Statistics version 20.0 (IBM Corp., Armonk, NY, USA). All values are expressed as mean \pm standard deviation. Univariate differences between the $\mathrm{L}$ and $\mathrm{P}$ group were assessed using independent-sample $t$ tests or the MannWhitney $U$ test for data that were not normally distributed. For all statistical analyses, the type 1 error was set at $5 \%$ and $p<0.05$ was considered to be significant.

\section{Results}

All patient characteristics and operative details are given in Table 1. The indications for lumbar interbody fusion surgery in this study included degenerative spondylolisthesis $(n=14)$ and lumbar canal stenosis $(n=16)$. Four patients underwent fusion at L2-3, 8 patients at L3-4, and 18 patients at $L 4-5$. The operation times ranged from 54 to $152 \mathrm{~min}$ (mean, $98.2 \pm 29.1 \mathrm{~min}$ ). Operative blood loss ranged from 4 to $332 \mathrm{ml}$ (mean, $54.4 \pm 70.1$ $\mathrm{ml}$ ). The length of hospitalization ranged from 9 to 26 days (mean, $16.3 \pm 4.5$ days). There were no intraoperative complications related to general condition, and no patients underwent reoperation for mispositioned pedicle screws. Intraoperative endplate injury was identified in 5 of the 30 patients (16.7\%). Age, sex, height, body weight, BMI, $\mathrm{Hb}$ level, estimated blood loss, and length of stay did not differ between the $\mathrm{L}$ and $\mathrm{P}$ groups. However, the operation time was 34 min longer for the $\mathrm{P}$ group $(111.9 \pm 25.0 \mathrm{~min})$ than for the $\mathrm{L}$ group $(77.5 \pm$ $22.2 \mathrm{~min}, p<0.01$ ) (Table 2). No significant differences were observed between the pre- and postoperative lumbar lordosis, segmental lordosis, change in lumbar lordosis or segmental lordosis, or segmental translation (Table 3).

\section{Discussion}

Since the introduction of the PPS technique in Japan in 2005, posterior spinal surgery has become less invasive, and PPSs are now used widely in the surgical treatment of infections, tumors, and trauma [9-11]. The new Viper Prime $^{\mathrm{TM}}$ is characterized by integration of the screw and stylet. Until now, it has been difficult to access the downside PPS insertion angle with the patient in the
(B)

(A)

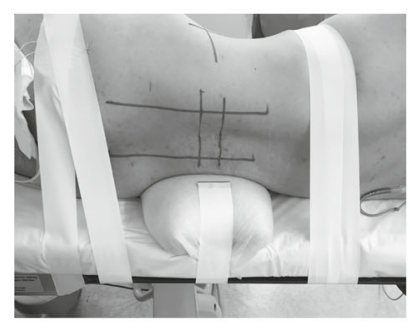

(C)

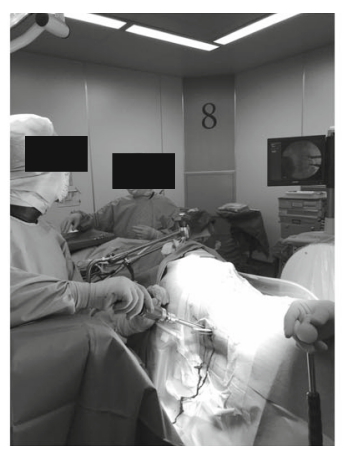

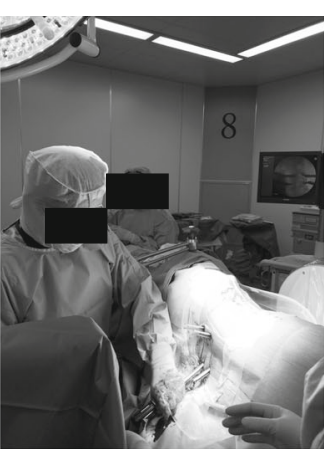

Fig. 2 a Intraoperative images demonstrating placement of the PPS using the Viper Prime ${ }^{\mathrm{TM}}$ with the patient in the lateral decubitus position. Marking the location of the incision. $\mathbf{b}$ Upside PPS placement. c Downside PPS placement 
Table 1 Demographic and clinical data

\begin{tabular}{ll}
\hline Patients $(n)$ & 30 \\
Age (years) & $70.8 \pm 8.5$ \\
Female & $13(43.3 \%)$ \\
Height (cm) & $159.9 \pm 9.3$ \\
Body weight (kg) & $62.4 \pm 11.7$ \\
Body mass index (kg/m ${ }^{2)}$ & $24.5 \pm 3.5$ \\
Diagnosis & \\
$\quad$ LCS & 16 \\
$\quad$ DS & 14 \\
Spine levels & \\
$\quad$ L1-2 & $0(0 \%)$ \\
L2-3 & $4(13.3 \%)$ \\
L3-4 & $8(26.7 \%)$ \\
$\quad$ L4-5 & $18(60.0 \%)$ \\
Blood loss (ml) & $54.4 \pm 70.1$ \\
Time in operating room (min) & $98.2 \pm 29.1$ \\
Length of stay (days) & $16.3+4.5$
\end{tabular}

LCS lumbar spinal canal stenosis, DS lumbar degenerative spondylolisthesis. All values are in mean \pm standard deviation

lateral decubitus position because of the limited working space between the operating table and fluoroscopy. The new PPS system allows the surgeon to create a working space between the operating table (patient's back) and the fluoroscopy which has not been possible in earlier third-generation PPS systems that require insertion of a hollow PPS through the guide wire. Using the Viper Prime $^{\mathrm{TM}}$ with the patient in the lateral decubitus position allows the PPS to be inserted easily.

Previous studies have shown that pedicle screw insertion using $3 \mathrm{D}$ neuronavigation is more secure than conventional insertion techniques [12-14]. Instruments such as computed tomography (CT) fluoroscopy (O-arm system) and navigation, which image the anatomical structures of the spine during surgery, are not available at many facilities. In the lateral decubitus position, the Viper Prime ${ }^{\mathrm{TM}}$ system can be used to insert PPSs with the patient in the lateral decubitus position because the fluoroscope can be used without the need for additional specialized medical instruments.

One advantage of the guide wire-less PPS system is that because the PPS can be inserted with the patient in the lateral decubitus position without the need for repositioning, this method may be used to correct vertebral slippage at the same time as the XLIF. The trick in compensation for slippage is to insert the upside PPS first, pass the rod a little further than the measurement, and then use the XLIF approach to remove the disc material. This is needed because the special operative window needed for XLIF interferes with fluoroscopy, and it can be difficult to evaluate the position of the screw and rod by fluoroscopy. After the disc is removed, the slip is corrected, the caudal setscrew is loosened, the XLIF cage is then inserted, and the downside PPS is inserted. In the future, we plan to determine how much correction can be made with this technique (Fig. 3).

The second advantage is shortening of the operation time, which should also improve the patient's experience by hastening their return home and recovery. In the current study, hospital stay was an average of 16 days. Japanese social healthcare system may have influenced the length of hospital stays. As a reason for this, although not all, we basically aim at about 2 weeks as an indication of hospital stay including a rehabilitation period when elderly patients can return home. In addition, it is thought that the hospital stay might have been extended because dialysis patients and diabetes mellitus patients were included. On the other hand, the

Table 2 Comparison of two groups

\begin{tabular}{llll}
\hline Characteristic & P group $(n=18)$ & L group $(n=12)$ & $p$ value \\
\hline Age (years) & $69.7 \pm 7.3$ & $72.4 \pm 10.2$ & 0.305 \\
Sex $(\mathrm{M}, \mathrm{F})$ & 11,7 & 6,6 & 0.632 \\
Height $(\mathrm{cm})$ & $160.8 \pm 9.3$ & $158.7 \pm 9.5$ & 0.662 \\
Body weight $(\mathrm{kg})$ & $63.5 \pm 13.1$ & $60.9 \pm 9.7$ & 0.415 \\
Body mass index $\left(\mathrm{kg} / \mathrm{m}^{2}\right)$ & $24.6 \pm 3.6$ & $24.2 \pm 3.5$ & 0.787 \\
Blood loss $(\mathrm{ml})$ & $69.0 \pm 83.8$ & $14.4 \pm 35.0$ & 0.095 \\
Pre-ope Hb $(\mathrm{g} / \mathrm{dl})$ & $13.6 \pm 1.9$ & $12.6 \pm 1.5$ & 0.439 \\
First post-ope Hb (g/dl) & $12.1 \pm 2.1$ & $-1.6 \pm 0.9$ & 0.545 \\
Change in Hb pre-ope to first post-ope $(\mathrm{g} / \mathrm{dl})$ & $-1.6 \pm 1.0$ & $77.5+22.2$ & 0.983 \\
Time in operating room (min) & $111.9+25.0$ & $16.8+5.1$ & $<0.01$ \\
Length of stay (days) & $16.0+4.2$ & 0.573 \\
\hline All values
\end{tabular}

All values are in mean \pm standard deviation pre-ope preoperative, post-ope postoperative 
Table 3 Radiological outcomes between two groups

\begin{tabular}{llll}
\hline Characteristic & $P$ group $(n=18)$ & $L$ group $(n=12)$ & $p$ value \\
\hline Pre-ope lumbar lordosis (degree) & $33.9 \pm 12.8$ & $30.7 \pm 11.3$ & 0.545 \\
Post-ope lumbar lordosis (degree) & $34.8 \pm 11.7$ & $28.3 \pm 10.3$ & $-2.4 \pm 7.1$ \\
$\begin{array}{l}\text { Change in lumbar lordosis pre-ope } \\
\text { to post-ope (degree) }\end{array}$ & $1.7 \pm 7.5$ & & 0.158 \\
Pre-ope segmental lordosis (degree) & $3.0 \pm 4.6$ & $4.0 \pm 5.6$ & $6.4 \pm 3.6$ \\
Post-ope segmental lordosis (degree) & $5.7 \pm 4.3$ & $2.4 \pm 3.0$ \\
Change in segmental lordosis pre-ope & $2.3 \pm 4.5$ & & 0.158 \\
to post-ope (degree) & & $4.1 \pm 4.0$ & 0.285 \\
Pre-ope segemental translation (mm) & $2.0 \pm 5.4$ & $1.5 \pm 2.5$ & 0.465 \\
Post-ope segmental translation (mm) & $1.2 \pm 3.9$ & $2.5 \pm 2.1$ & 0.200 \\
Change in segmental translation & $0.8 \pm 2.8$ & & 0.755 \\
pre-ope to post- ope (mm) & & & 0.072 \\
\hline
\end{tabular}

All values are in mean \pm standard deviation

pre-ope preoperative, post-ope postoperative

average total mean operation time was $77 \mathrm{~min}$ and blood loss was $32 \mathrm{ml}$ with the guide wire-less method. The difference in operation time was 34 min between the prone PPS and the lateral PPS. Our results are consistent with those reported by Tohmeh et al. [15], who found an average difference of $38 \mathrm{~min}$ (range $30-84 \mathrm{~min}$ ) in the repositioning time between the lateral decubitus and prone positions. In a study of the use of lateral PPSs by Blizzard and Thomas [8], 72 patients were treated with lateral interbody fusion and PPS in the lateral decubitus position. A mean total operation time of 87.9 min (1.1 fused levels per patient) and blood loss of $53 \mathrm{ml}$ were found. They reported a shorter operation time with PPS insertion in the lateral decubitus position but a similar PPS breach rate as that reported previously in the prone position [16-18]. In our study, we did not analyze the PPS breach rate, but none of the patients experienced paralysis or leg pain after surgery or required reoperation to replace the screws. The third advantage of the

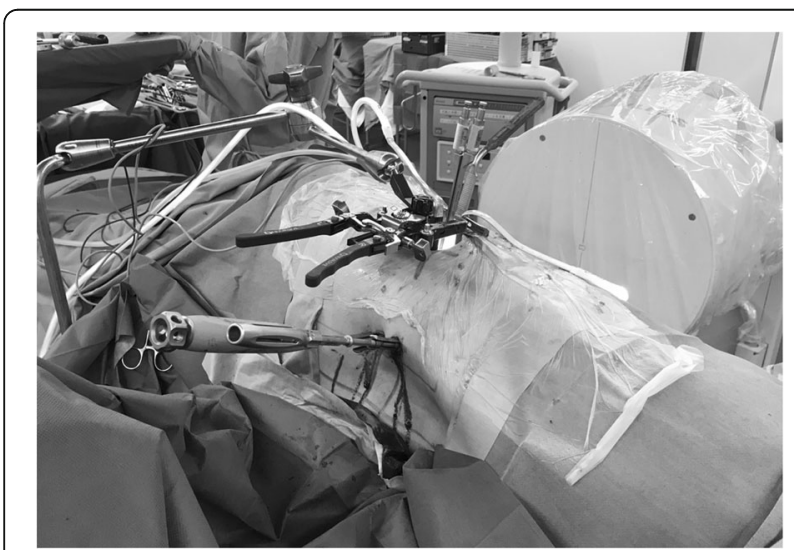

Fig. 3 Correction of lumbar spondylolisthesis using XLIF and upside PPS with the patient in the lateral decubitus position guide wire-less method is that there is no risk of guide wire problems [19] given that the Viper Prime ${ }^{\mathrm{TM}}$ system does not use guide wires. Another advantage of the PPS insertion method with the patient in the lateral decubitus position method is that patient repositioning is not required, which should reduce medical costs [8]. Although calculating the cost of each minute in the operating room is complex, the use of the lateral PPS technique after the LLIF may reduce cost by reducing the time in the operating room.

The limitations of this study are the retrospective design and that all lateral PPS surgeries were performed at a single center by a single surgeon. Although the latter may have introduced some bias to our study, we feel that inclusion only of patients treated by a single surgeon created a more uniform cohort for study, especially given that the data were collected from a series of cases. Another limitation is that the sample size was very small. However, to our knowledge, this is the first report on the use of the lateral PPS and fluoroscopy with a guide wire-less technique without patient repositioning after XLIF surgery. Despite the small sample size, we found that this technique significantly shortened the operation time. In addition, we did not evaluate long-term clinical outcomes and fusion rates. We think that further studies are needed to evaluate the effectiveness as well as the short- and long-term impact of this method on clinical outcomes and fusion rates compared to conventional surgical approaches.

A final limitation of this study is the lack of information about the insertion accuracy for the lateral PPSs. CT scans were not routinely obtained postoperatively to assess the fusion or screw position because no patients exhibited postoperative complications related to insertion of the screws, and we could not justify the risk of exposure to further CT imaging. 


\section{Conclusion}

In this study, the all-lateral technique requiring a single patient position after XLIF surgery is a feasible modification of the standard procedure used with fluoroscopy and new PPS systems. Operative blood loss, length of hospital stay, and correction of lordosis did not differ between patients treated with the all-lateral technique and those who were repositioned in the standard procedure. However, the operation time was reduced by $34 \mathrm{~min}$ in the all-lateral technique. This new technique reduces the time and need for staffing associated with intraoperative repositioning and may lead to significant cost savings.

\section{Abbreviations}

3D: Three-dimensional; AP: Anteroposterior; BMI: Body mass index; Hb: Hemoglobin; LLIF: Lateral lumbar interbody fusion; OLIF: Oblique lumbar interbody fusion; PPS: Percutaneous pedicle screw

\section{Acknowledgements}

Not applicable.

\section{Authors' contributions}

All authors have read and approved the manuscript. AH conceived and designed the study, and interpreted the results. DS acquired the data and interpreted the results. MS acquired the data and interpreted the results. MW conceived and designed the study, and interpreted the results.

\section{Funding}

The authors report no funding for this work.

\section{Availability of data and materials}

Data are available upon request from the corresponding author.

\section{Ethics approval and consent to participate}

The study protocol was reviewed and approved by the Committee on Ethics and the Institutional Review Board of Tokai University School of Medicine (18R-315), the House Clinical Study Committee, and Profit Reciprocity Committee. Because this study was retrospective, the requirement for informed consent was not deemed necessary.

\section{Consent for publication}

Not applicable.

\section{Competing interests}

The authors declare that they have no competing interests.

Received: 25 March 2019 Accepted: 29 August 2019

Published online: 05 September 2019

\section{References}

1. Elowitz EH. Central and foraminal indirect decompression in MIS lateral interbody fusion (XLIF): video lecture. Eur Spine J. 2015;24(Suppl 3):449-50.

2. Oliveira L, Marchi L, Coutinho E, Pimenta L. A radiographic assessment of the ability of the extreme lateral interbody fusion procedure to indirectly decompress the neural elements. Spine. 2010;35(26 Suppl):S331-7.

3. Ozgur BM, Aryan HE, Pimenta L, Taylor WR. Extreme lateral interbody fusion (XLIF): a novel surgical technique for anterior lumbar interbody fusion. Spine J. 2006;6(4):435-43.

4. Phillips FM, Isaacs RE, Rodgers WB, Khajavi K, Tohmeh AG, Deviren V, Peterson MD, Hyde J, Kurd M. Adult degenerative scoliosis treated with XLIF: clinical and radiographical results of a prospective multicenter study with 24-month follow-up. Spine. 2013;38(21):1853-61.

5. Rodgers WB, Gerber EJ, Patterson J. Intraoperative and early postoperative complications in extreme lateral interbody fusion: an analysis of 600 cases. Spine. 2011;36(1):26-32.

6. Ziino C, Konopka JA, Ajiboye RM, Ledesma JB, Koltsov JCB, Cheng I. Single position versus lateral-then-prone positioning for lateral interbody fusion and pedicle screw fixation. J Spine Surg. 2018;4(4):717-24.
7. Hilis A, Roldan L, Suarez D, Laez R, Agueros JA, Barquero A. "One-Shot" CT image navigated circumferential fusion in a single lateral decubitus position: surgical technique. J Neurosurg Sci. 2017;61(4):429-37.

8. Blizzard DJ, Thomas JA. MIS single-position lateral and oblique lateral lumbar interbody fusion and bilateral pedicle screw fixation: feasibility and perioperative results. Spine. 2018;43(6):440-6.

9. Sahai N, Faloon MJ, Dunn CJ, Issa K, Sinha K, Hwang KS, Emami A. Shortsegment fixation with percutaneous pedicle screws in the treatment of unstable thoracolumbar vertebral body fractures. Orthopedics. 2018;41(6): e802-6.

10. Mobbs RJ, Park A, Maharaj M, Phan K. Outcomes of percutaneous pedicle screw fixation for spinal trauma and tumours. J Clin Neurosci. 2016;23:88-94.

11. Lin TY, Tsai TT, Lu ML, Niu CC, Hsieh MK, Fu TS, Lai PL, Chen LH, Chen WJ. Comparison of two-stage open versus percutaneous pedicle screw fixation in treating pyogenic spondylodiscitis. BMC Musculoskelet Disord. 2014;15:443.

12. Shin BJ, Njoku IU, Tsiouris AJ, Hartl R. Navigated guide tube for the placement of mini-open pedicle screws using stereotactic 3D navigation without the use of K-wires: technical note. J Neurosurg Spine. 2013;18(2): 178-83.

13. Shin BJ, James AR, Njoku IU, Hartl R. Pedicle screw navigation: a systematic review and meta-analysis of perforation risk for computer-navigated versus freehand insertion. J Neurosurg Spine. 2012;17(2):113-22.

14. Kosmopoulos $V$, Schizas C. Pedicle screw placement accuracy: a metaanalysis. Spine. 2007;32(3):E111-20.

15. Tohmeh AG, Watson B, Tohmeh M, Zielinski XJ. Allograft cellular bone matrix in extreme lateral interbody fusion: preliminary radiographic and clinical outcomes. ScientificWorldJournal. 2012;2012:263637.

16. Chapman TM, Blizzard DJ, Brown CR. CT accuracy of percutaneous versus open pedicle screw techniques: a series of 1609 screws. Eur Spine J. 2016; 25(6):1781-6.

17. Ohba T, Ebata S, Fujita K, Sato H, Haro H. Percutaneous pedicle screw placements: accuracy and rates of cranial facet joint violation using conventional fluoroscopy compared with intraoperative three-dimensional computed tomography computer navigation. Eur Spine J. 2016;25(6):1775-80.

18. Kwan MK, Chiu CK, Lee CK, Chan CY. Comparison between percutaneous fluoroscopic-guided and conventional open pedicle screw placement techniques for the thoracic spine: a safety evaluation in human cadavers. Bone Joint J. 2015;97-B(11):1555-61.

19. Ishii K, Kaneko Y, Funao H, Ishihara S, Shinohara A, Nakanishi K, Hikata T, Fujita N, Iwanami A, Hosogane N, et al. A novel percutaneous guide wire (swire) for percutaneous pedicle screw insertion: its development, efficacy, and safety. Surg Innov. 2015;22(5):469-73.

\section{Publisher's Note}

Springer Nature remains neutral with regard to jurisdictional claims in published maps and institutional affiliations.

\section{Ready to submit your research? Choose BMC and benefit from:}

- fast, convenient online submission

- thorough peer review by experienced researchers in your field

- rapid publication on acceptance

- support for research data, including large and complex data types

- gold Open Access which fosters wider collaboration and increased citations

- maximum visibility for your research: over $100 \mathrm{M}$ website views per year

At $\mathrm{BMC}$, research is always in progress.

Learn more biomedcentral.com/submissions 